\title{
Erratum to: Optical Networks
}

\author{
Giancarlo de Marchis ${ }^{1}$ and Roberto Sabella ${ }^{2}$ \\ 1 Fondazione Ugo Bordoni, Italy \\ 2 Ericsson Telecomunicazioni, Italy
}

\section{Erratum to: \\ G. de Marchis and R. Sabella (Eds.) \\ Optical Networks \\ DOI: $10.1007 / 978-0-387-35398-2$}

The book was inadvertently published with an incorrect name of the copyright holder. The name of the copyright holder for this book is: (c) IFIP International Federation for Information Processing. The book has been updated with the changes. 